\title{
Recent and future articles
}

\section{Recent articles \\ Population Trends}

\section{No. 133 Autumn 2008}

\section{Features:}

Have national trends in fertility between 1986 and 2006 occurred evenly across England and Wales?

Nicola Tromans, Eva Natamba, Julie Jefferies and Paul Norman

Home births in the UK, 1955-2006

Andrea Nove, Ann Berrington and Zoe Matthews

The development of a Postcode Best Fit methodology for producing population estimates for different geographies

Andy Bates

Reports:

Marriages abroad, 2002-07

Divorces in England and Wales during 2007

Subnational population projections for local authorities in Wales

Internal migration estimates for local and unitary authorities in England and

Wales, year to mid-2007

Live births in England and Wales, 2007: area of residence

Death registrations in England and Wales, 2007: area of residence

Annual Updates:

Civil partnerships during 2007: United Kingdom

\section{No. 134 Winter 2008}

Features:

Ageing and mortality in the UK - National Statistician's annual article on the population

Karen Dunnell

Population 'turnover' and 'churn' - enhancing understanding of internal migration in Britain through measures of stability

Adam Dennett and John Stillwell

The National Population Projections Expert Advisory group: results from a

questionnaire about future trends in fertility, mortality and migration

Chris Shaw

Annual Updates:

Births in England and Wales, 2007

\section{Future articles}

List is provisional and subject to change

\section{Population Trends No. 138 Winter 2009 \\ Publication December 2009}

\section{Features:}

- The United Kingdom's population: The National Statistician's annual article on the population

- Changes in religion of the population of Great Britain, 2005-2008

- Developing an Address Register for the 2011 Census

\section{No. 135 Spring 2009}

Features

The 2011 Census taking shape: the selection of topics and questions

lan White and Elizabeth McLaren

UK resident population by country of birth

Amy Ellis

What does the 2001 Census tell us about the new parliamentary constituencies? Julien Anseau

\section{Reports}

A demographic portrait of Northern Ireland

Marriages in England and Wales, 2007

\section{No. 136 Summer 2009}

Features:

A comparison of the characteristics of childless women and mothers in the ONS Longitudinal Study

Martina Portani and Simon Whitworth

Estimating the cohabiting population

Ben Wilson

Have women born outside the UK driven the rise in UK births since 2001?

Nicola Tromans, Julie Jefferies and Eva Natamba

Subnational analysis of the ageing population

Sarah Blake

The 2011 Census taking shape part II: Methodological and technological developments

lan White

\section{Reports:}

Patterns of fatherhood in England and Wales, 1964-2007

Decennial life tables, 2000-02

2006-based marital status and cohabitation projections for England and Wales Marriages and divorces during 2006 and adoptions in 2007; England and Wales 


\section{Recent articles}

\section{Health Statistics Quarterly}

\section{No. 40 Winter 2008}

\section{Features:}

Regional differences in male morality inequalities using the National Statistics Socio-economic Classification, England and Wales, 2001-03 Veronique Siegler, Ann Langford and Brian Johnson

Geographical trends in infant mortality: England and Wales, 1970-2006 Paul Norman, lan Gregory, Danny Dorling and Allan Baker

Standardised Mortality ratios - the effect of smoothing ward-level results Allan Baker, Martin Ralphs and Clare Griffiths

Reports:

Infant and perinatal mortality in England and Wales by social and biological factors, 2007

Excess winter mortality in England and Wales, 2007/08 (provisional) and 2006/07 (final)

Health expectancies in the United Kingdom 2004-06

Life expectancy at birth and at age 65 by local areas in the United Kingdom, 2005-07

Cancer incidence and mortality in the United Kingdom and constituent countries, 2003-05

\section{No. 41 Spring 2009}

\section{Features:}

Trends in cancer survival in Spearhead Primary Care Trusts in England, 1998-2004

Libby Ellis, Bernard Rachet, Anjali Shah, Sarah Walters, Michel P Coleman, Nicola Cooper and Susan Westlake

Death certification following MRSA bacteraemia, England, 2004-05

Levin Wheller, Cleone Rooney and Clare Griffiths

Estimating conception statistics using gestational age information from NHS Numbers for Babies data

Yuan Huang Chow and Nirupa Dattani

An investigation into the impact of question change on estimates of General Health Status and Healthy Life Expectancy

Michael Smith and Chris White

Reports:

Conceptions in England and Wales, 2007

Congenital anomalies notifications 2007, England and Wales

\section{Future articles}

List is provisional and subject to change

\section{Health Statistics Quarterly No. 44 Winter 2009 Publication November 2009}

\section{Features:}

Demographic, behavioural and socio-economic influences on the survival of retired people - evidence from a ten-year follow-up study of the General Household Survey, 1994-95

Cause and regional variations of adult female mortality in England and Wales, 2001-03 using the National Statistics Socio-economic Classification Reports:

Infant and perinatal mortality in England and Wales by social and biological factors, 2008

Life expectancy at birth and at 65 by local areas in the United Kingdom, 2006-08

Excess winter mortality in England and Wales, 2008/09 (provisional) and 2007/08 (final)

Infant and perinatal mortality 2008: health areas, England and Wales

\section{No. 42 Summer 2009}

Features:

Social inequalities in adult female mortality by the National Statistics Socioeconomic Classification, England and Wales, 2001-03

Ann Langford and Brian Johnson

Multivariate analysis of infant death in England and Wales in 2005-06, with focus on socio-economic status and deprivation

Laura Oakley, Noreen Maconochie, Pat Doyle, Nirupa Dattani and Kath Moser An update to measuring chronic illness, impairment and disability in national data sources

Chris White

Reports:

Gestation-specific infant mortality by social and biological factors among babies born in England and Wales in 2006

\section{No. 43 Autumn 2009}

Features:

Unemployment, mortality and the problem of health-related selection: evidence from the Scottish and England and Wales (ONS) Longitudinal Studies Tom Clements, Paul Boyle and Frank Popham

\section{Reports:}

Deaths involving MRSA: England and Wales, 2008

Jane Carter

Deaths involving Clostridium difficile: England and Wales, 2008

Jane Carter

Deaths related to drug poisoning in England and Wales, 2008

Claudia Wells

Cancer incidence and mortality in the United Kingdom and constituent countries, 2004-06

Susan Westlake

Unexplained deaths in infancy, England and Wales, 2008

Julie Messer

Death registrations in England and Wales, 2008, causes Christopher Hill
Individual articles are available from the ONS data and publications website at www.statistics.gov.uk/cci/articlesearch.asp Complete back editions of Health Statistics Quarterly and Population Trends are available at:

Health Statistics Quarterly: www.statistics.gov.uk/statbase/Product. asp?vlnk=6725

Population Trends: www.statistics.gov.uk/statbase/Product.asp?vlnk=6303 